\title{
El Decamerón, la Peste Negra y el Coronavirus
}

\author{
The Decameron, the Black Plague and the Coronavirus
}

Saniel E. Lozano-Alvarado ${ }^{1}$

\section{RESUMEN}

Ante el fenómeno de la pandemia universal del coronavirus en el ámbito mundial, en el presente trabajo partimos del reconocimiento de una aproximación de la literatura a la realidad, punto de partida frecuente en el proceso de creación literaria, especialmente en la narración. Según lo expuesto, la literatura no puede juzgarse solamente teniendo en cuenta su función artística, sino su relación con las diversas formas de la realidad: social, económica, cultural, etc. Se traza un paralelismo entre la "peste negra", que se originó en Oriente, de donde pasó a Italia y a los demás países europeos, y la pandemia actual del coronavirus. En el reconocimiento de esta situación se ubica el punto de partida del desarrollo de la estructura y contenido del "Decamerón", la notable obra de Giovanni Boccaccio: conjunto de cuentos referidos por siete muchachas y tres jóvenes varones, cada uno de los cuales relata diez cuentos. La decisión la adoptaron como una medida de aislamiento y entretenimiento para eludir el contagio de la epidemia.

Palabras clave: Epidemia, peste negra, coronavirus.

\section{ABSTRACT}

Faced with the phenomenon of the universal pandemic of coronavirus at the world level, in this work we start from the recognition of an approximation of literature to reality, a common starting point in the process of literary creation, especially in storytelling. According to the above, literature cannot be judged only taking into account its artistic function, but rather its relationship with the various forms of reality: social, economic, cultural, etc. A parallel is drawn between the "black plague", which originated in the East, from where it passed to Italy and the other European countries, and the current pandemic of the coronavirus. In the recognition of this situation is the starting point of the development of the structure and content of the "Decameron", the remarkable work of Giovanni Boccaccio: set of stories referred to by seven girls and three young men, each of whom recounts ten stories. The decision was taken as a measure of isolation and entertaining to evade the spread of the epidemic.

Keywords: Epidemic, black plague, coronavirus.

1 Profesor de Interpretación de textos y de literatura infantil, Universidad Privada Antenor Orrego, Trujillo. Doctor Honoris Causa por la Universidad Nacional de Trujillo, Trujillo, Perú.

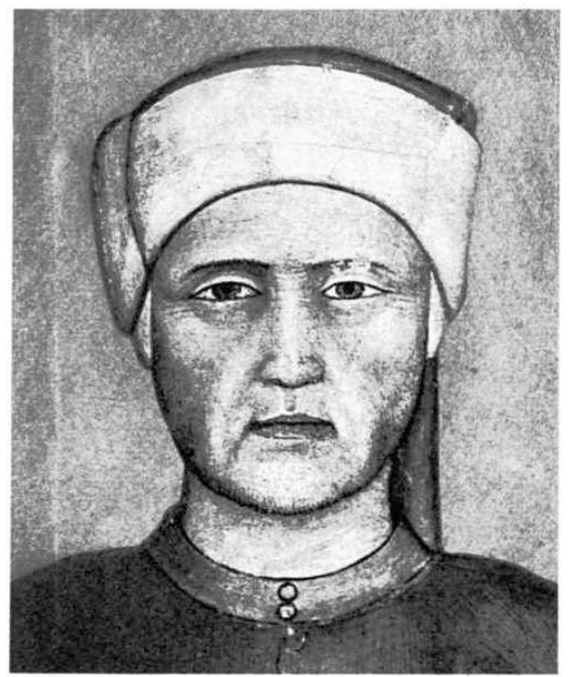

Retrato tradicional de Bocaccio de los frescos de la Capilla Española de Santa María Novella, Florencia.

\section{INTRODUCCIÓN}

a epidemia del coronavirus actualiza - la cuestión de la relación entre la literatura y la realidad, categorías que se integran de manera inseparable, sobre todo si se tiene en cuenta que toda obra literaria parte de alguna forma de la realidad, la cual puede ser trasladada, modificada o recreada en la producción de un determinado texto, de donde resulta la literatura realista o la de ficción, según la obra resultante "reproduzca" o "recree" la realidad, o se aleje de ella. Sobre todo, en el primer caso, la obra literaria resulta siendo un símbolo o metáfora de la realidad física, social, económica, cultural, histórica, etc. 
Este asunto, precisamente, explica la naturaleza, valor y trascendencia de $E l$ Decamerón, de Giovanni Boccaccio, y cuyo tema general parte precisamente de la terrible epidemia de la peste negra, la más atroz de la era cristiana de entonces, y que al igual que el coronavirus contemporáneo, se originó en oriente, de donde pasó a Italia y a las demás naciones europeas. El foco de la epidemia fue la ciudad de Florencia.

Desde luego, las épocas son diferentes y muy distantes; pero ambas epidemias y la actitud de los gobiernos de las diferentes naciones y la población generan no solo paralelismos sino convergencias y coincidencias. Aquí radica, entonces, uno de los valores primordiales de la literatura, que no solo puede juzgarse con criterios estéticos sino por su distancia o aproximación con la realidad.

De manera particular, el tema de las epidemias y enfermedades contagiosas que han generado innumerables víctimas ha sido el referente y punto de partida que se ha plasmado en varias obras literarias. La relación es amplia, pero de manera general podemos señalar estos ejemplos: "El Decamerón"; "La peste", de Albert Camus; "Casas muertas", del venezolano Manuel Otero Silva; "El amor en los tiempos del cólera", de Gabriel García Márquez; "Los hermanos Arango", de José María Arguedas"; "Calixto Garmendia", de Ciro Alegría; "La ciudad de los tísicos", de Abraham Valdelomar. En el presente trabajo ofrecemos una semblanza del autor, la aparición y manifestaciones de la "peste negra", punto de partida para el contenido de "El Decamerón", la actitud de la población, la situación y actuación de los personajes de la mencionada obra y el valor e importancia de la literatura, especialmente de la novela aludida.

\section{BOCCACCIO Y SU OBRA}

Giovanni Boccaccio nació el 17 de julio de 1313, en Florencia. Pasó su juventud en Nápoles y empezó a estudiar Derecho. En 1318 se estableció en su tierra natal, donde fue testigo de la terrible epidemia de la peste negra, ocurrida en 1348 y entre cuyas víctimas estuvieron su padre y su madrastra. Escribió su trascendental obra entre los años 1349 y 1351. Murió el 21 de diciembre de 1375 en su casa de Certaldo que muchos, incluido él mismo, creían su ciudad natal. Aún se conserva el texto que él mismo dictó para su entierro: "Fue su padre Boccaccio; su patria, Certaldo; su afición, la poesia".

Más información y explicaciones sobre su vida y obra nos ofrece el Diccionario de Literatura Universal (2003: 129 a 130):

En realidad, nació de una relación ilegítima de un rico mercader y pasó su infancia en Florencia, donde inició sus estudios de latín. Hacia 1328 su padre le envió a Nápoles para que estudiase y practicase comercio en la sucursal bancaria de los Bardi, familia muy relacionada con la corte de Anjou. No se adaptó a esa tarea y durante seis años se dedicó a estudiar derecho canónico, actividad a la que también renunció para volcarse con fervor a la literatura, sobre todo en la lectura de los clásicos, de los poetas en lenguas romances, de la narrativa cortesana y de los cantares populares. Empezó entonces a componer versos y prosas y a frecuentar a los eruditos de la corte napolitana, así como los numerosos actos y fiestas de la alta sociedad de la ciudad. Estas intensas experiencias culturales y sentimentales, así como su característica y constante inclinación a convertir en fábula la realidad vivida, encontraron expresión en sus primeras obras: "La caza de diana", "El filocolo", "El filostrato", "Teseida", "Ameto", "Vida nueva de Dante" (uno de los autores que más admiró), "La amorosa visión", "Elegía de madonna Fiammetta", "El Corbaccio" y otras más. A pesar de que aún denotan ciertas exuberancias sentimentales y eruditas retóricas, estas obras tienden a reflejar atentamente la realidad a través de un análisis directo y sincero, y con una serena y objetiva comprensión de la urgencia de las pasiones. 
Sobre su sincera dedicación a la poesía escribió el mismo escritor: "Sea lo que fuese de los demás, por lo que a mí respecta diré que la naturaleza me inclinó, desde el vientre de mi madre, a las meditaciones poéticas, y por lo que de ello puedo juzgar, nací solamente para tal menester".

\section{LA PESTE NEGRA}

En el prólogo a su conjunto de cuentos (1999: 8 a 14), el célebre cuentista refiere que la terrible epidemia se originó "por efecto de los cuerpos celestes o más grandes pecados por justo designio de nuestro Señor sobre los mortales". Esto significa que, según su interpretación, la tragedia fue resultado de un castigo divino ante tanta maldad de los seres humanos. Pero volviendo a la epidemia: ésta comenzó algunos años antes en Oriente, de donde pasó hacia Italia y Occidente, es decir a los demás países especialmente europeos.

Según lo expuesto, la epidemia del coronavirus resulta reproduciendo una antigua realidad en cuanto a su origen en Oriente. Ante el avance del terrible mal, la ciudad fue limpiada y purgada de todas las suciedades; se prohibió la entrada de posibles infectados; se adoptaron todas las medidas sanitarias, religiosas $\mathrm{y}$ humanas, incluidas las procesiones para suplicar humildemente la misericordia de Dios.

En cuanto a los síntomas, la enfermedad se manifestaba por el constante flujo de sangre que les venía a las víctimas por las narices; a hombres y mujeres atacadas por el terrible mal les salían en la ingle o bajo la tetilla izquierda algunos bultos tan grandes como huevos; después se multiplicaban manchas negras en brazos y piernas. Ante tal situación, lo grave era que ninguna curación o tratamiento médico era efectivo.
Por otro lado, no se conocía el origen del mal ni la medicina apropiada. Entonces las víctimas morían generalmente dentro del tercer día de contraída la infección. Nada podían hacer los médicos, así como tampoco resultaban eficaces las diversas medidas sanitarias y de curación. El contagio era terrible "no solamente al hablar o acercarse a los enfermos, sino incluso al tocar las ropas que ellos vestían o cualquier otra cosa que hubiese estado en contacto con ellos". Y no solo se contagiaban las personas, sino también los animales y bestias al ser tocados por ellas.

Otro hecho asociado con la actual situación del coronavirus es que, para prevenir el contagio, las autoridades prohibieron visitar a los enfermos y entrar en sus casas, así como reunirse con otras personas. Se procuraba pues un absoluto aislamiento. "Ocioso sería decir que un ciudadano no se preocupaba del otro, y que casi ningún vecino cuidaba de su vecino, y que los mismos familiares, pertenecientes a la misma sangre, muy pocas veces, o ninguna, se visitaban". Los mismos sepelios perdieron sus formalidades y protocolos: "habiendo llegado a la iglesia, sin preocuparse en rezar algún oficio $y$ en buscar la debida sepultura, sino rezando una o dos oraciones, los lanzaban en la primera fosa que hallaban abierta".

Al mismo tiempo, otros infectados, a cualquier hora del día o de la noche morían en plena calle, "sin que de sus vecinos ni demás fuese sabida su muerte, salvo por lo que el olor de los cadáveres daba noticia de ello". Del mismo modo, en cuanto a los servicios fúnebres, "cuando el religioso se disponía a enterrar a un muerto, hallaba a lo menos siete u ocho cadáveres". En los cementerios se enterraban a las víctimas por centenares.

En el recuento general, Boccaccio ofrece este panorama desolador que dejó la mortal, cruel e indolente epidemia, ante la cual la propia ciencia médica nada pudo hacer: 
¿Qué se puede acerca de esto decir o contar (dejando ahora la comarca, y volviendo a la ciudad), salvo que tanta y tal fue la crueldad del cielo, y, en parte, de los hombres, que entre el mes de mayo y el siguiente mes de junio, por la virulencia de la enfermedad tanto como por la poca diligencia que acerca de los enfermos se hacía, se cree y afirma que dentro de los muros de la ciudad de Florencia más de cien mil criaturas humanas fueron arrebatadas de esta presente vida, número que, por ventura, antes que aquel malaventurado accidente ocurriese, no se pensaba que en toda ella existiera? ¡Oh, cuántos grandes palacios, cuántas hermosas y bien edificadas casas, cuántas nobles habitaciones y moradas, llenas y pobladas de nobles moradores y grandes señores y damas, de los mayores hasta el menor servidor quedaron vacías y solas! ¡Cuántas familias, cuántos excelentes linajes, cuántos grandes y ricos heredamientos y posesiones, cuántas y cuán preciosas riquezas se vieron, sin heredero y legitimo sucesor, desamparadas! ¡Cuántos valerosos y nobles hombres, cuántos y cuán hermosas, graciosas y galanas damas, cuántos gentiles y alegres hidalgos que, no a juicio del pueblo común, más al de Galeno, Hipócrates y Esculapio, serían juzgados bien complexionados y sanos, a la mañana comieron con sus compañeros y amigos, y a la noche cenaron en el otro mundo, con sus antecesores! (1999: 13 y 14).

\section{El DECAMERón}

En cuanto al origen, desarrollo y contenido de la notable obra de Boccaccio, en una época en que no se habían desarrollado los medios de comunicación masiva; cuando no había periódicos, revistas, radio, ni ningún medio electrónico; cuando tampoco se habían inventado el telégrafo ni el teléfono, la comunicación entre naciones, regiones

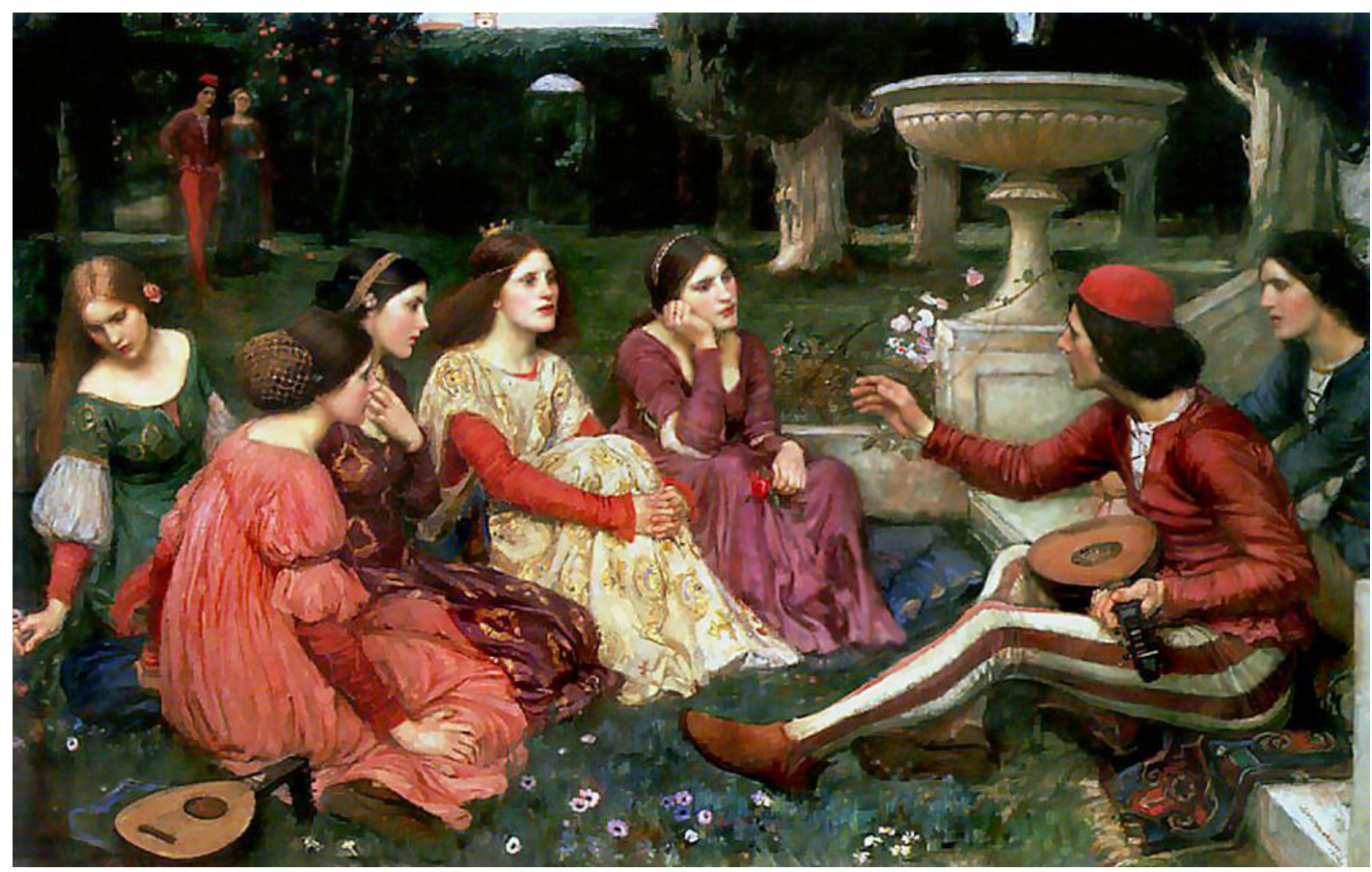

A Tale from The Decameron. Óleo de John William Waterhouse (1916). Lady Lever Art Gallery (Port Sunlight, United Kingdom). 
y ciudades contribuía al aislamiento de las poblaciones. Por eso, no solo Florencia sino también Nápoles, Milán y otras ciudades, en realidad, cada una funcionaba como estado autónomo. Por tanto, igual que ahora, se adoptaron medidas de "cierre de fronteras", aislamiento social y otras medidas previsoras. Como consecuencia, las personas y familias sufrían terriblemente por el encierro, la tensión, la depresión, la angustia, el aburrimiento.

Ante esta terrible epidemia extremadamente contagiosa, para evitar la enfermedad, el contagio o simplemente las consecuencias del encierro domiciliario, un grupo de siete jóvenes muchachas: Pampinea, Flameta, Filomena, Emilia, Laureta, Neifile y Elisa, sin haberse conocido antes, "sino por casualidad se juntaron en una parte de la iglesia" lamentándose de los estragos de la epidemia, así como de los problemas del aislamiento en sus casas y alojamientos, decidieron abandonar la ciudad y establecerse lejos, hasta que pasara la terrible epidemia.

Al advertir las muchachas que también ingresaron a la iglesia tres jóvenes: Filóstrato, Pánfilo y Dioneo, les comunicaron sus problemas y proyectos, que los jóvenes, también en la misma dramática situación, aceptaron inmediatamente. Entonces, todo el grupo se dirigió al campo, donde las siete muchachas y los tres jóvenes, después de analizar distintos modos de entretenimientos, decidieron que cada uno, durante los días de evasión y confinamiento, como medio de liberación de la mortal epidemia, así como para aliviar la tensión, debería relatar diez cuentos de temática afín o similar, que en total sumarían cien, llamados también por el autor como novelas.

A partir de esta decisión se desarrolla el contenido propiamente dicho de la notable obra valorada por muchos críticos, en cuyo conjunto destaca la opinión de Pilar Gómez Bedate, profesora de Literatura Comparada de la Universidad de Puerto Rico, en Mayagüez, en el artículo "El cuento en la Edad Media" (1984: 296):

Toda esta varia y rica materia, Boccaccio la adapta a su tiempo, la sitúa en lugares de Europa y el Mediterráneo por todos conocidos, en las ciudades italianas, en París, en Alejandría, les da personajes con nombre y apellidos conocidos (en muchas ocasiones amigos suyos), les hace moverse por la nostalgia del inmediato pasado o la disponibilidad por la vida presente con que se movían las gentes de su siglo y las hace participar en las aventuras guerreras (como las cruzadas) o las mercantiles (...), en los éxitos o desastres que él o sus antepasados inmediatos vivieron. En la frontera entre el mundo medieval y el renacentista, el Decamerón, en su rica complejidad, recoge los temas y los preceptos de la variada tradición medieval culta europea y les infunde la vida de un mundo nuevo.

También el investigador de la literatura Ramón D. Perés, en su "Historia universal de la literatura", se ha expresado en estos términos:

"La Comedia humana se le ha llamado, por contraste con La Divina Comedia, y realmente es un espejo, quizá algo deformador, a veces de la vida diaria en el siglo XIV, aunque bien pudiera aplicarse a todos los tiempos la maliciosa observación de aquel pagano nutrido de cultura clásica, como lo demuestra la celebrada descripción de la peste de Florencia (inspirada, al parecer, en la que Tucídides trazó de la peste de Atenas) (...) Boccaccio recoge donde puede cuanto necesita y no olvida que algo tiene de sangre francesa" (1974: 512).

Acta Herediana vol. 64, N 1, enero 2021 - junio 2021 


\section{CONCLUSIONES}

1. La literatura no puede considerarse solo bajo concepciones o criterios estéticos, sino también a partir de sus relaciones con la realidad en sus diversas formas y manifestaciones: física, social, económica, histórica, afectiva, filosófica, etc.

2. Entre la realidad de la cual parte y la literatura resultante hay una serie de relaciones que no necesariamente se pueden comprobar mediante pruebas, como en la investigación científica experimental, sino aceptarse por convicción y convencimiento.

3. En determinados contextos y situaciones, la literatura, especialmente la narración, reproduce, recrea, transforma la realidad inicial $\mathrm{u}$ originaria y se plasma en la obra resultante, que, entonces, no es enteramente o siempre, una obra realista, sino de ficción.

4. Uno de los temas recurrentes que toma y desarrolla (no copia ni retrata) la literatura es la salud, las enfermedades, el rol y función de la medicina.

5. Varios autores en las literaturas de sus respectivos contextos humanos y sociales han plasmado en sus obras, especialmente en la narración (cuento y novela) el tema de las enfermedades y epidemias.

6. Uno de los autores que toma como tema referente el proceso, manifestaciones y consecuencias de la epidemia de su obra es el italiano Giovanni Boccaccio, autor de "El Decamerón", que permite trazar un excepcional paralelo entre la peste negra, ocurrida en Europa (Italia) en la EdadMediayelcoronaviruscontemporáneo de alcance mundial.

\section{Referencias Bibliográficas}

1. Boccaccio, Giovanni. Decamerón. Barcelona: Editorial Planeta, edición especial para EPENSA, Empresa Periodística Nacional; 1999.

2. De Perés, Ramón. Historia universal de la literatura. Barcelona: Editorial Ramón Sopena, S.A.; 1974.

3. Gómez Bedate, Pilar. El cuento en la Edad Media. En: Historia universal de la literatura (De la antigüedad al Renacimiento. Bogotá: Editorial Oveja Negra; 1984.

4. Océano. Diccionario de literatura universal. Barcelona: Editorial Océano; 2003.

\section{CorRespondencia}

Saniel Lozano, sanielozanoal@hotmail.com

Fecha de recepción: 09-09-2020.

Fecha de aceptación: 11-01-2021.

Conflicto de interés: ninguno, según el autor.

Financiamiento: por el autor. 